ately distal to the renal arteries the haemodynamic situation in the aorta and renal arteries is changed. The laminar blood stream becomes turbulent and the renal arteries must bear the whole resulting kinetic energy. A vasospasm of the vasa afferentia might be induced. The volume flow, already reduced by turbulence, is further reduced. Atheromatous emboli, released and dispersed from the clamped aorta (Thurlbeck and Castleman, 1957), and vasoactive substances, released by the reninangiotensin-mechanism (Kountz et al., 1963), appear to be complementary factors. If the aorta is cross-clamped distal to the renal arteries for a maximum of two hours renal function is temporarily disturbed. As was shown experimentally, tubular necrosis arises after infrarenal cross-clamping for over two hours. The frequency of this complication after aortic surgery is given as between 3.8 and $20 \%$ (Kountz et al., 1963).

Different prophylactic measures have been recommended. Nanson and Noble (1959) injected local anaesthetics and ganglion-blockers into the renal pedicle; Barry et al. (1961) gave osmotic active mannitol during operation and in the immediate postoperative phase. Finally, it was suggested that adiphenine hydrochloride or Arfonad (trimetaphan camsylate) should be injected into the renal pedicle during operation (Doolan et al., 1960).

Our two cases of acute contralateral renal failure after unilateral renal artery reconstruction were probably caused by the same mechanisms as mentioned above. During the operations on the right kidney the aorta was cross-clamped for 31 and 77 minutes respectively, the clamp being placed in both cases obliquely - that is, from the right cranial to the left caudal aspect. The blood flow to the left kidney appeared to be ensured that way. In both cases, however, turbulence in the aorta, spasms of the vasa afferentia, and resulting decrease in flow of the open renal artery obviously caused renal ischaemia and parenchymal damage.

If in unilateral renal artery reconstruction an aortic clamp is placed in such a way that the contralateral renal artery is still perfused, then damage of this kidney is possible even after a short cross-clamping time.

\section{Summary}

Two cases of contralateral acute reversible renal failure after unilatcral renovascular operation are reported. The failure was proved by intravenous pyelography, renography, and ureteral catheterization. Three months later renal function was normal again, no treatment having been necessary. Probably the same factors play a part in failure of the untouched kidney as in renal failure after aortic surgery. The haemodynamic situation in the aorta is altered when the aorta is cross-clamped immediately distal to the renal arteries. This results in renal ischaemia, and, in other cases, unilateral anuria and renal insufficiency.

Requests for reprints should be addressed to Dr. J. F. Ammann, Department of Surgery A, Kantonsspital, Zurich.

\section{REFERENCES}

Barry, K. G., et al. (1961). New Engl. 7. Med., 264, 967.

Doolan, P. D., Wiggins, R. A., Thiel, G. B., Lee, K. J., and Martinez, E. (1960). Amer. 7. Med., 28, 895.

Foster, J. H., Adkins, R. B., Chamberlain, N. O., Symbas, P. N., and Harris, A. P. (1963). f. Amer. med. Ass., 183, 451.

Gagnon, J. A., Bolt, D. A., Clarke, R. W., and Geever, E. F. (1960).

Surgery, 47, 240.
Kountz, S. L., Tuttle, K. L., Cohn, L. H., Eschelman, L. T., and Cohn, R. (1963). F. Amer. med. Ass., 183, 447.

McGonigle, D. J., Seipel, R. S., and Wylie, E. J. (1961). Surgery, 49, 235.

Morris, G. C., jun., DeBakey M. E., Crawford, E. S., Cooley, D. A., and Zanger,

Nanson, E. M., and Noble, J. G. (1959). Surgery, 46, 388.

Powers, S. R., Boba, A., and Stein, A. (1957). Surgery, 42, 156

Scheitlin, W. A. (1967). Ergebn. inn. Med. Kinderheilk., 26, 45.

Schwarz, H. F., Scheitlin, W. A., and Senning, §. (1967). Langenbecks Arch. klin. Chir., 319, 1182. Szilagyi, D. E., Smith, R. F., and Whitcomb, J. G. (1959). Arch. Surg.,

Thurlbeck, W. M., and Cas:leman, B. (1957). New Engl. ł. Med., 257, 442.

\title{
Plasma Cortisol Levels in Lung Cancer
}

\author{
IVAN LICHTER,* F.R.C.S., F.R.A.C.S. ; NANCY E. SIRETT,* B.SC., A.N.Z.I.C.
}

Brit. med. F., 1968, 2, 154-156

Lung cancer, especially the oat-cell type, may be associated with Cushing's syndrome, and in these cases the tumour produces a substance indistinguishable from pituitary corticotrophin (Liddle et al., 1965). In patients dying of lung cancer an increase in width of the adrenal cortex has been demonstrated (Sholiton et al., 1961 ; Caranasos and Ruebner, 1963). Segaloff et al. (1962) established that this was not due to the prolonged stress of the disease, as patients with non-malignant chronic pulmonary lesions showed no evidence of adrenocortical hyperactivity. Increased morning plasma 17-hydroxycorticoid levels in lung cancer were reported by Werk and Sholiton (1960). Eighteen of the 22 subjects studied had secondary deposits and some were very ill. In only a few individual patients could the level be regarded as abnormally high, though the mean levels were generally higher than those in a control series. That raised plasma corticoid levels can be expected in patients dying from a variety of illnesses was demonstrated by Sandberg et al. (1956).

* Department of Surgery and N.Z.M.R.C. Endocrinology Research Unit, University of Otago Medical School, Dunedin, New Zealand.
Segaloff et al. (1962) also assessed adrenal function in patients with lung cancer. Plasma corticoid levels (Porter and Silber chromogens) measured in 26 patients were found to be generally higher than in those of six control patients who had benign lung lesions. The values in this latter group were similar to those in six normal ambulatory male controls. This study was later continued by Hatch et al. (1965). They investigated 100 patients with lung cancer and Porter-Silber chromogens were again measured. Seventy-one of them had elevated plasma corticoid levels, and in 25 of these the level was above $20 \mu \mathrm{g} . / 100 \mathrm{ml}$. (4-11 $\mu \mathrm{g} . / 100 \mathrm{ml}$. was thought to be normal). Only one of these patients had Cushing's syndrome. The authors felt that an abnormally high plasma corticoid level in patients with pulmonary disease was added evidence that the lesion might be malignant. They noted that four to six weeks after surgical removal of a lung cancer the plasma corticoid levels returned to normal and the level was found to rise again with recurrence of the lung cancer.

We have undertaken this study to endeavour to assess the diagnostic and prognostic significance of the plasma cortisol 
levels in patients with lung cancer. We felt it important to have adequately screened controls because of the known variability of the cortisol level in relation to a multitude of factors such as emotional disturbance, pain, stress, obesity, recent investigations, drug therapy-for example, steroids, oral contraceptives. The study was therefore planned to eliminate these variables so far as possible. It was designed also to take account of the normal diurnal variations of the plasma cortisol levels (Mills, 1966).

\section{Material and Methods}

On the first or second day of admission heparinized blood ( $7 \mathrm{ml}$. BD Vacutainer) was taken from selected hospital patients with no known endocrine disorder. Samples were taken at 4.30 p.m. \pm 30 minutes and at 8.30 a.m. \pm 30 minutes next morning. The afternoon specimen was stored in the refrigerator overnight, and plasma was stored frozen $\left(-17^{\circ}\right.$ C.) if the estimation could not be done immediately. Samples were also taken from healthy ambulant adults and plasma cortisol was estimated fluorimetrically by a method similar to that of Mattingly (1962) (Purves and Sirett, 1967). The method is specific for 11-hydroxycorticoids. One $\mathrm{ml}$. of plasma was extracted with $5 \mathrm{ml}$. of methylene chloride, and $4 \mathrm{ml}$. of the methylene chloride extract was reacted with $1.5 \mathrm{ml}$. of fluorescent reagent (sulphuric acid: rectified spirits, 2:1). Fluorescence was measured 10 minutes \pm 10 seconds after mixing, a Locarte fluorimeter being used. The method is quick and reliable. The standard deviation of 25 estimations on nine different days on a plasma sample was $1.38 \mu \mathrm{g}$., the mean being $18.9 \mu \mathrm{g} . / 100 \mathrm{ml}$.

Twenty-six patients with proved lung cancer and 24 patients with no lung cancer (mainly mechanical disorders such as hiatus hernia, inguinal hernia, varicose veins, etc.) were included in the study. In each case the following details were noted: age, sex, obesity, steroid therapy, use of oral contraceptives, drug therapy, and recent investigations and operations. A record was made of whether the patient appeared to be emotionally disturbed or in pain, the endocrine status was noted, and a final diagnosis was recorded. On the basis of these observations some patients were withdrawn, the most common reason being obesity or unproved diagnosis.

\section{Results}

The plasma cortisol levels of the three groups studied are given in the Table and the Chart.

The mean group differences between the lung cancer and the no-lung-cancer group were significant. However, as shown on the scatter diagram, the variation of the individual levels is so wide that it is impossible to separate individuals by their plasma cortisol levels into the two groups. The levels found in the healthy ambulant adults also suggest that single estimations from individuals fall within a very wide range and would have limited diagnostic value.

Morning and Afternoon Plasma Cortisol Levels in Hospital Patients with Lung Cancer, Patients with No Lung Cancer, and Healthy Ambulant Adults

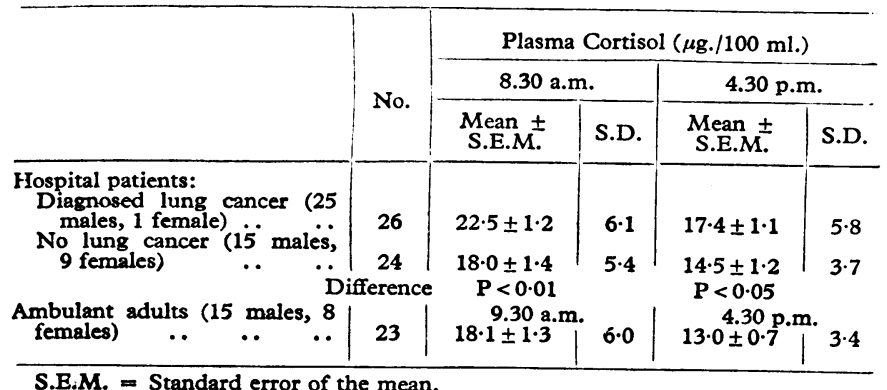

S.E.M. = Standard error of the mean.
S.D. = Standard deviation.
The diurnal variation was evident in the group means of all three groups, but within each group there are individuals who failed to show a reduced level in the afternoon. The incidence of these irregularities appears to be similar in each group (see Chart). The mean difference a.m.-p.m. and the standard deviation (in parentheses) were: diagnosed lung cancer 5.1 (4.4) $\mu \mathrm{g} . / 100 \mathrm{ml}$., no lung cancer 3.5 (5.5) $\mu \mathrm{g} . / 100 \mathrm{ml}$., and ambulant adults $5.1(5.1) \mu \mathrm{g} . / 100 \mathrm{ml}$.

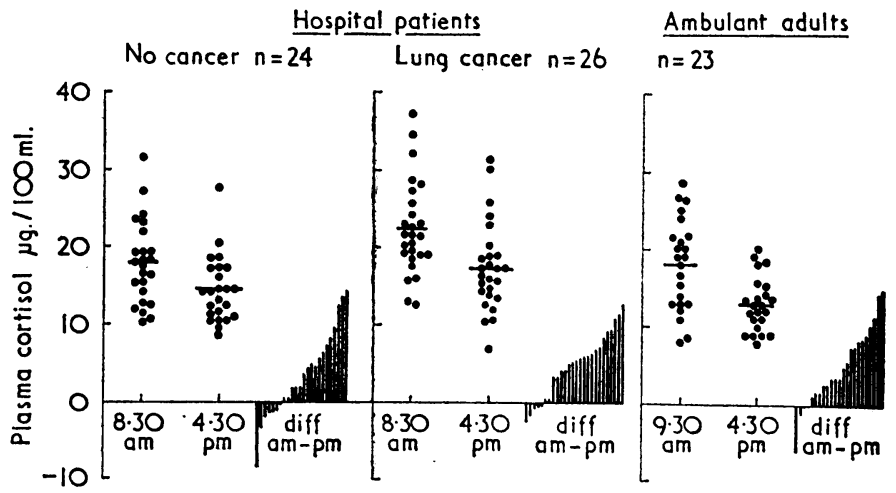

Distribution of morning and afternoon plasma cortisol levels in hospital patients with no lung cancer, diagnosed lung cancer, and healthy ambulant adults.

\section{Discussion}

The distribution of plasma 11-hydroxycorticoids in our hospital patients is similar to those reported by others using a fluorimetric method (McGill et al., 1967 ; McHardy-Young et al., 1967) but higher than those reported by Liddle (1966), who measures 17-hydroxycorticoids as Porter-Silber chromogens. We recommend caution when comparing results of plasma cortisol estimations from different laboratories because of the variability in methods of measurement (James et al., 1967).

This investigation has failed to support the suggestion that plasma cortisol estimations would be useful diagnostically to identify lung cancer patients. The group means did show a significant elevation in the lung cancer patients, both in the morning and in the afternoon, and this supports the previous recorded evidence of hyperadrenal function in lung cancer as seen in the increase in adrenal size at necropsy (Segaloff et al., 1962 ; Caranasos and Ruebner, 1963). Few patients in this series have, however, shown plasma cortisol levels that are clearly beyond the range found in non-cancer patients or in normal ambulant subjects.

We have found a wide daily variation in individuals in a study carried out in a group of 11 ambulant adults observed over the period Monday to Friday. The highest individual variation was $14 \mu \mathrm{g} . / 100 \mathrm{ml}$. during th: five-day study. These results emphasize the breadth of the normal range of cortisol concentration in human plasma and the limitations of single plasma cortisol levels on individuals. We had considered that there might be a difference in the characteristics of the changes in the morning and afternoon plasma cortisol levels, but the diurnal variation between the cancer and no-cancer groups did not differ significantly. It is possible that cortisol levels taken at midnight, when the lowest circadian rhythm levels are recorded, might show a clear divergence from normal, but this has not been practicable. Cope (1966) has shown that hyperadrenal activity can be detected by examining the plasma cortisol levels at midnight.

\section{Summary}

Using a fluorimetric method, we have measured the morning and afternoon levels of plasma cortisol in a group of patients 
with lung cancer and a control group with no lung cancer. The group mean levels both in the morning and in the afternoon were greater in the lung cancer patients, but the range of individual values within each group does not permit the test to be used diagnostically.

Thanks are due to Dr. G. R. Simpson, Dr. A. G. Rothwell, and Dr. L. G. Barnes for assistance with this study, and to Dr. H. D. Purves, Director of N.Z.M.R.C. Endocrinology Research Unit, for help and advice.

\section{REFERENCES}

Caranasos, G., and Ruebner, B. H. (1963). Arch. Path., 76, 263. Cope, C. L. (1966). Brit. med. Y.. 2, 847, 914.
Hatch, H. B., jun., Segaloff, A., and Ochsner, A. (1965). Ann. Surg.161,645 .

James, v. H. T., Townsend, J., and Fraser, R. (1967). F. Endocr., 37,

Liddle, G. W. (1966). Arch. intern. Med., 117, 739.

Liddle, G. W., Givens, J. R., Nicholson, W. E., and Island, D. P. (1965). Cancer Res., 25, 1057 .

McGill, P. E., Greig, W. R., Browning, M. C. K., and Boyle, J. A. (1967). Ann. rheum. Dis., 26, 123.

McHardy-Young, S., Harris, P. W. R., Lessof, M. H., and Lyne, C (1967). Brit. med. 7., 2, 740.

Mattingly, D. (1962). \%. clin Path., 15, 374

Mills, J. N. (1966). Physiol. Rev., 46, 128.

Purves, H. D., and Sirett, N. E. (1967). N.Z. med. 7., 66, 811.

Sandberg, A. A., Eik-Nes, K., Migeon, C. J., and Samuels, L. T. (1956) F. clin. Endocr., 16, 1001 .

Segaloff, A., Hatch, H. B., and Rongone, E. L. (1962). Cancer Chemo-

ther. Rep., No. 16, p. 343 . 105 .

Werk, E. E., jun., and Sholiton, L. J. (1960). Cancer, 13, 469.

\title{
Calf Pain in the Post-thrombotic Syndrome
}

\author{
DAVID NEGUS, ${ }^{*}$ M.A., D.M., M.CH., F.R.C.S.
}

Brit. med. Y., 1968, 2, 156-158

Extensive thrombophlebitis of the deep veins of the leg is usually followed by the syndrome of swelling, induration, ulceration, and pain. This pain is of two sorts: firstly, the discomfort which is associated with distended varices and ulceration, and, secondly, the calf pain, which has been described as "bursting" in nature (Bauer, 1948). Other names for calf pain in the post-thrombotic syndrome are "cruralgia orthostatica" (Arnoldi, 1965) and "venous claudication" (Cockett and Lea Thomas, 1965).

Patients with post-thrombotic damage to the deep veins of the leg may be divided into two groups (Cockett and Lea Thomas, 1965). Thrombophlebitis confined to those veins which lie distal to the inguinal ligament (the femoral, popliteal, , and calf veins) is followed by recanalization, which results in valvular incompetence of the deep and perforating veins (Homans, 1917 ; Cockett, 1953). Iliac vein thrombosis, on the other hand, is of ten followed by grossly inadequate recanalization and permanent stenosis (Wanke and Gumrich, 1950; Eufinger, Diethelm, and May, 1961 ; Luke, 1962 ; Cockett, Lea Thomas, and Negus, 1967). This stenosis is commonly, though not invariably, localized to the left common iliac vein, where it is crossed by the right common iliac artery. In spite of collateral formation, stenosis usually results in permanent obstruction to venous return and a rise in pressure in the distal veins (Negus and Cockett, 1967).

No previous attempt has been made to compare the clinical features of these groups of patients, and this paper reports the results of observations and investigations of the clinical features, with particular reference to the incidence, significance, and mechanism of calf pain.

\section{Incidence and Significance of Pain}

Forty-four patients with post-thrombotic damage to the deep vein of the lower limb were divided into two groups on the results of peripheral and iliac phlebography and of venous pressure measurement in the foot and femoral vein (Negus and Cockett, 1967), and from observations made during surgical operation.

Group 1.-Seventeen patients were shown to have incompetence of the peripheral deep veins and perforating veins without functional obstruction to venous return.
Group 2.-Twenty-six patients had stenosis of the iliac veins or inferior vena cava sufficient to cause functional obstruction to blood flow, in addition to peripheral deep-vein incompetence. In one other patient normal peripheral deep veins were associated with proximal obstruction to venous blood flow.

There was no significant difference in age, sex, or age at onset between the two groups.

Studies were also made of five normal subjects and five patients with primary lymphoedema.

\section{Investigations}

History.-Each patient was questioned specifically about pain: its site and nature, precipitating factors, measures taken to relieve it, and the social incapacity which resulted from it.

Physical Examination.-Particular attention was paid to the presence or absence of varicose veins, incompetent perforating veins, ankle ulceration, and swelling of the affected leg.

"Stepping Test."-All 17 group 1 patients and 26 group 2 patients underwent a "standard stepping test," which consisted of marking time at a speed of 80 steps a minute, each foot being lifted to half the height of the opposite knee. Patients were encouraged to continue the exercise until they complained of severe discomfort.

\section{Results}

History.-Only one patient in group 1 complained of more than " heaviness" or fatigue, and most stated that, apart from the ulcer, they were perfectly comfortable. One worked as a woodman, walking eight to nine miles (13 to $14.5 \mathrm{~km}$.) a day, and another walked the beat as a special constable after his day's work as an accountant. No patient in group 1 was forced to change his employment. Every patient with post-thrombotic obstruction to venous return (group 2) complained of calf pain, which was exacerbated by exercise and which was often described as "bursting" in nature. The pain was usually confined to the calf and was occasionally described as spreading to the thigh. It was sometimes felt on prolonged standing, and

* Lecturer, Department of Surgery, St. Thomas's Hospital, London S.E.1 